\title{
LA GENÉTICA REPRODUCTIVA
}

\author{
XAVIER VENDRELL ${ }^{1}$ \\ Unidad de Genética Reproductiva, Sistemas Genómicos
}

\begin{abstract}
RESUMEN. El desarrollo de la Genética está estrechamente relacionado con los avances de las técnicas de reproducción asistida desde los orígenes de éstas a principios de los años 70 . Un gran número de estudios genéticos han sido desarrollados especialmente dirigidos a las parejas con deseo reproductivo. Estos estudios permiten determinar el riesgo genético, establecer un diagnóstico o prever el pronóstico reproductivo en estas parejas. Los estudios genéticos están especialmente dirigidos a las mujeres, los varones o los embriones generados mediante técnicas de fecundación in vitro. El presente trabajo pretende revisar los diferentes estudios que actualmente están a disposición de los futuros progenitores. Es especialmente importante establecer las causas de la infertilidad, cuando existe, para poder indicar un tratamiento adecuado. Asimismo, resulta capital clarificar el riesgo genético para la descendencia en determinados escenarios, para poder evitar la aparición de trastornos graves en la descendencia. En este contexto, el asesoramiento genético reproductivo preconcepción es enormemente importante y debe estar a disposición de los pacientes.
\end{abstract}

PALABRAS CLAVE: genética reproductiva, asesoramiento genético, preconcepción, preimplantación, herencia, reproducción, fecundación in vitro, descendencia.

\section{The reproductive genetics}

ABSTRACT. The development of Genetics is closely related with the assisted reproduction technologies from its beginnings at early 1970s. Very high quantities of genetic tests have been developed for couples. These tests allow stablishing the genetic risk, the diagnosis or the reproductive prognosis depending on the couple. The tests are designed to women, men or preimplantation embryos generated by in-vitro fertilization techniques. This paper aims to review the different studies that are currently available to future parents. The establishment of infertility causes is crucial in order to indicate proper treatments. Furthermore, the estimation of genetic risk is decisive to avoid serious disorders in the offspring. In this context, the preconception genetic counselling is extremely important and should be available to patients.

KEY WORDS: reproductive genetics, genetic counselling, preconception, preimplantation, inheritance, reproduction, in-vitro fertilization, offspring.

\section{INTRODUCCIÓN}

El último registro de la ESHRE (European Society of Human Reproduction and Embriology) ofrece datos de 1314 centros de reproducción humana asistida en 33 países del continente europeo, en el año 2011 (Kupka et al., 2016). Este registro recoge más de 600.000 tratamientos de reproducción asistida y estima que, en un contexto histórico, cerca de seis millones y medio de niños han nacido en el mundo mediante la aplicación de las técnicas de reproducción asistida (TRA). Asimismo, el EIM Consortium (European IVF-Monitoring Consortium) establece que España es el país europeo que más ciclos de reproducción hu-

1 Responsable de la Unidad de Genética Reproductiva, Sistemas Genómicos. Parque Tecnológico de Valencia. 
mana asistida registra (Apter et al., 2016). En el año 2014 (último año recogido en el registro oficial de la Sociedad Española de Fertilidad del año 2016; https:// www.registrosef.com/public/docs/sef2014_IAFIV.pdf), se realizaron en nuestro país cerca de 110.000 tratamientos.

La gran mayoría de estas parejas acuden a las unidades de fecundación in vitro (FIV) por problemas de fertilidad. La infertilidad afecta a aproximadamente una de cada seis parejas en los países occidentales. Además de la edad materna avanzada, el deterioro en la calidad de los gametos, los hábitos tóxicos y los factores ambientales, son algunos de los «nuevos» factores de riesgo. Este hecho reconoce a la infertilidad como un problema de salud pública y su tratamiento está incluido en la cartera de servicios del sistema público de salud.

En este contexto, el objetivo de las Unidades de Reproducción Asistida (URA) es ayudar a estas parejas en su proyecto reproductivo a tres niveles bien establecidos: el asesoramiento, el diagnóstico y el tratamiento. Durante este proceso de acompañamiento, en muchos casos es necesaria la valoración de su caso desde un punto de vista genético. En este sentido, la Genética Reproductiva ofrece una visión muy especializada. Desde el punto de vista formal, la Genética Reproductiva es la disciplina que estudia la relación entre las características genéticas de cada persona y su capacidad reproductiva. En concreto estudia la forma de trasmisión del material genético, el efecto de las anomalías del material genético sobre la reproducción, la trasmisión de anomalías genéticas a la descendencia y los eventuales efectos de las modificaciones epigenéticas de este material.

Desde el punto de vista genético, las URA se encuentran con dos grupos de pacientes claramente diferenciados. Por una parte, las parejas con un riesgo elevado de trasmisión de una enfermedad genética a su descendencia. Este grupo de pacientes incluye las parejas con algún miembro portador, o afectado, de un trastorno genético susceptible de ser trasmitido y además aquellas parejas que, por sus características, tienen un riesgo elevado de generar embriones genéticamente alterados, que son incompatibles con la vida y se traduce en una infertilidad prolongada. Estas parejas, en la mayoría de los casos son fértiles. Algunos ejemplos son las parejas portadoras o afectas de enfermedades hereditarias, las mujeres de edad reproductiva avanzada, o los varones con alteraciones en la calidad seminal.

Por otro lado, están las parejas que presentan una infertilidad de base genética. En estos casos, uno de los miembros de la pareja (o los dos) es portador de un trastorno genético que le impide la reproducción de forma natural. Un ejemplo claro de este último caso son los varones que presentan una agenesia de vasos deferentes a causa de una mutación asociada al gen de la fibrosis quística. Estos varones no tienen espermatozoides en el eyaculado. Otro ejemplo son las mujeres portadoras del síndrome del cromosoma X-frágil. Estas mujeres presentan, en muchos casos, una menopausia precoz con un fallo ovárico a edades muy tempranas. En estos casos la causa de la infertilidad es claramente genética. 
En base a esta clasificación, resulta de radical importancia establecer el riesgo genético real en cada caso. En sentido general, las parejas manifiestan el deseo de descendencia sana. Pero antes de proponer un estudio genético en particular, es necesario delimitar de forma más clara el concepto de «descendencia sana». Desde el punto de vista anticipatorio, no todos los trastornos genéticos pueden ser prevenidos. Es necesario asesorar de forma clara, tanto a los facultativos como a los pacientes, acerca de los alcances y limitaciones de los estudios genéticos, de forma que esta información les sea de utilidad para la toma de decisiones. Esta vinculación entre la Genética y la reproducción asistida está ampliamente reconocida por la comunidad científica (Soini et al., 2006), lo cual ha permitido el desarrollo de una serie de estudios genéticos encaminados a establecer el riesgo genético, el diagnóstico o el pronóstico reproductivo en estas parejas.

El objetivo del presente trabajo es revisar los estudios que ofrece actualmente la genética reproductiva. Estos estudios están orientados en tres escenarios posibles: la mujer, el varón y los embriones en estadios preimplantación.

\section{Estudios GENÉticos EN LA MUJER}

\subsection{Cariotipo en la mujer}

El cariotipo en sangre periférica es el estudio que permite detectar anomalías en el número o en la estructura de los cromosomas. Puede ser también que ambos casos se den a la vez. Para determinar el cariotipo de un individuo, es necesario llevar a cabo un cultivo de células de la sangre, teñirlas y estudiarlas para ordenar los cromosomas, y verificar si su número o estructura es correcto. El cariotipo de un individuo no cambia con el tiempo. Las mujeres con una dotación cromosómica normal exhiben una fórmula cromosómica 46, XX, lo que significa que tienen 22 pares de cromosomas autosómicos (numerados del 1 al 22) y dos cromosomas sexuales $\mathrm{X}$ (ver figura 1). Los cromosomas sexuales pueden ser $\mathrm{X}$ o Y.

En ocasiones ocurre que el número de cromosomas de un individuo es distinto al total de 46. Este tipo de anomalías se conocen como «anomalías numéricas». Cuando las células han perdido un cromosoma presentan lo que se conoce como un monosomía para este cromosoma. En el caso que tenga un cromosoma de más, habrá trisomía para el cromosoma en cuestión. Las monosomías de los cromosomas autosómicos (del 1-22) suelen morir poco después de la concepción, ya que por lo general no son viables. En cambio, algunas trisomías pueden llegar a término (por ejemplo el síndrome de Down, el síndrome de Edwards o el síndrome de Pateau). Por otra parte, la anomalía más común en cuanto al número de cromosomas sexuales en la mujer es el Síndrome de Turner $(45, \mathrm{X} 0)$. Este síndrome se relaciona de forma clara con infertilidad o subfertilidad en la mujer (Grynberg et al., 2016). 


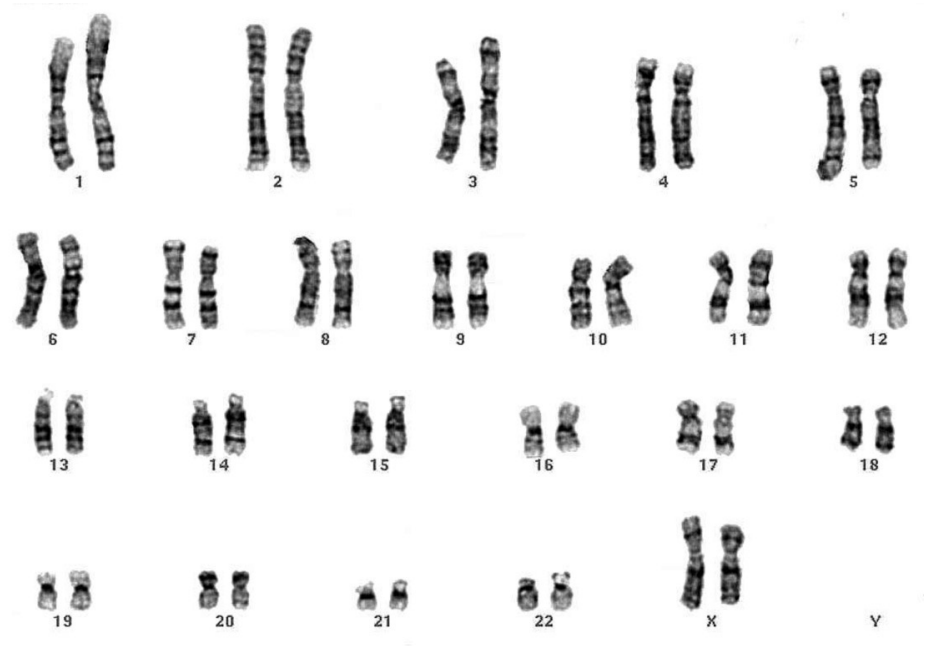

Figura 1. Imagen de un cariotipo normal de mujer, con formula cromosómica 46, XX. El patrón de bandas blancas y negras es específico de cada cromosoma y permite su identificación, además de detectar eventuales reordenamientos o alteraciones estructurales intracromosómicas.

Por otro lado, algunas pacientes son portadoras de alteraciones estructurales en los cromosomas. Las mujeres portadoras de estas alteraciones suelen ser asintomáticas. En estos casos, lo más común es que exista un intercambio de material genético entre dos cromosomas distintos (translocaciones), un reordenamiento de material genético dentro del mismo cromosoma (inversiones) o la pérdida de un fragmento cromosómico (deleciones) (para ampliar la información léase Gersen y Steven, 2013). La mayoría de estas anomalías provocan problemas de fertilidad; fallos de implantación, abortos a repetición o nacimientos con defectos genéticos, debido a que parte de los ovocitos de las mujeres portadoras están alterados y se generan embriones genéticamente anormales.

\subsection{Estudios genéticos en casos de abortos habituales}

La causa de los abortos de repetición es uno de los aspectos más controvertidos y desconocidos en el campo de la Medicina Reproductiva. Desde el punto de vista genético, algunas alteraciones muy bien conocidas se han asociado a los abortos recurrentes. En concreto, los reordenamientos cromosómicos estructurales son la causa de la gran mayoría de los abortos de repetición de etiología genética (Fryns y Van Buggenhout, 1998). Las parejas con uno de los miembros portadores de alguno de estos reordenamientos, dan lugar a embriones cromosómicamente desequilibrados que son incompatibles 
con la vida. Los pacientes portadores de las formas equilibradas suelen ser asintomáticos, como hemos dicho antes.

Otra de las causas asociadas a las pérdidas tempranas es la existencia de embriones aneuploides, fundamentalmente trisómicos. En la mayoría de los casos su origen es ovocitario, pero cada vez existen más datos acerca del origen espermático en cromosomas concretos. Por otro lado, en la mayoría de los casos la etiología concreta de la recurrencia en la pérdida del embarazo queda por determinar. No se conoce qué porcentaje de estos abortos puede deberse a una alteración en los genes relacionados con la sustentación del embarazo. Mutaciones en genes relacionados con procesos inflamatorios, trombosis y sistema cardiovascular, sistemas de detoxificación, segregación cromosómica, respuesta inmune, regulación hormonal, función placentaria o función mitocondrial, pueden estar relacionados con estas pérdidas gestacionales (revisado por Holly y Schust, 2009). En conclusión, la causa genética parece estar detrás de parte de los abortos recurrentes. No obstante, desde el punto de vista práctico, es difícil establecer un panel de estudios genéticos dirigidos al diagnóstico certero en estas parejas. En general, en estos casos se realiza el cariotipo y algunos estudios de genes relacionados con las trombofilias.

\subsection{Estudio de enfermedades hereditarias concretas}

Existen alteraciones genéticas concretas, más allá de alteraciones en el cariotipo, que repercuten en la capacidad reproductiva de las mujeres. Estas alteraciones se deben a mutaciones en genes muy concretos y que deben ser evaluadas en una consulta de asesoramiento genético preconcepción. La forma más típica es la mutación asociada al síndrome del cromosoma X-frágil. Se trata de la forma de retraso mental hereditario más frecuente, y se debe a una mutación en el gen FMR1, situado en el cromosoma X. Las mujeres portadoras suelen ser asintomáticas, pero manifiestan un fallo ovárico muy precoz, dando lugar a una menopausia a edades muy tempranas. Muchas de estas pacientes acuden a las unidades de FIV por problemas de fertilidad. Del mismo modo, una gran cantidad de genes están implicados en alteraciones de la capacidad reproductiva de las mujeres (revisado en Venkatesh, et al., 2014). Llegados a este punto es importante destacar el papel de los genes de "efecto materno». En los vertebrados, los procesos celulares críticos están orquestados por una serie de productos moleculares de origen ovocitario. Procesos clave como la fecundación, la fusión del genoma materno y paterno, las primeras divisiones celulares (mitosis) y la separación celular (citocinesis) dependen de moléculas depositadas en el ovocito durante la ovogénesis y que ejercen su función antes de la activación del genoma propio del embrión. Estas «moléculas maternas» son ácidos nucleicos (ARN mensajeros), proteínas y otras biomoléculas que están codificadas por un conjunto de genes. A estos genes se les conoce como "genes de efecto materno» y se describieron por primera vez en mamíferos en el año 2000 (Christians et al., 2000; Tong et al., 2000). Una vez se activa el genoma propio del zigoto, o del embrión en división (esto varía en función de la especie), 
estos genes de efecto materno dejan de ejercer su función. De este modo, muchos de estos genes tienen una contribución exclusiva en estas fases tempranas del desarrollo, no participan en procesos de desarrollo posterior (juvenil o adulto) y son los responsables de regular la embriogénesis temprana en la siguiente generación. Por esta razón, el conocimiento de estos genes resulta de radical importancia para el estudio de un proceso tan complejo en la vida adulta como es la preservación de la especie, es decir el éxito en la fecundación, el desarrollo embrionario temprano y la esperanza de vida reproductiva, en definitiva la fertilidad (revisado en Vendrell, 2013). Se ha descrito que mutaciones en estos genes están directamente relacionadas con la infertilidad.

\section{Estudios GENÉTICOS EN EL VARÓN}

En el caso de los varones los estudios genéticos se diferencian en función del tejido que se analiza, teniendo por tanto un valor somático o germinal. En el caso de los estudios realizados a partir de sangre periférica, tienen un valor somático y en este sentido diagnóstico. Por otro lado, los estudios que se realizan a partir de muestras de tejido testicular o eyaculado, tienen un valor germinal y, en la mayoría de los casos, pronóstico. En los últimos años este tipo de estudios en el varón han ido proliferando, de forma que la contribución del varón sobre la infertilidad de la pareja, cada vez está más claro. Los estudios genéticos más extendidos con un valor pronóstico, realizados sobre tejido germinal son: el estudio de la ploiodía (número de cromosomas) espermática, la fragmentación del ADN espermático y el análisis de la meiosis en tejido testicular (revisado en Vendrell et al., 2014). En cuanto a los estudios diagnósticos sobre sangre periférica destacan el cariotipo, el estudio de las microdeleciones del cromosoma Y y el gen CFTR (responsable de la fibrosis quística), además de una gran cantidad de análisis genéticos de genes concretos en casos de enfermedades específicas (revisado en Neto et al., 2016). A continuación se comentan brevemente los aspectos más relevantes de cada estudio.

\subsection{Estudios germinales: análisis de la ploidía espermática}

La técnica utilizada en estos análisis es la conocida como FISH (Fluorescent in situ hybridzation). Nos da información directa acerca del estado cromosómico de los gametos masculinos eyaculados que van a ser utilizados en una técnica de reproducción asistisa. Esta técnica permite la identificación del número de cromosomas presentes en una muestra espermática. Las alteraciones en el número de cromosomas paternos, se encuentran relacionados a mayor riesgo de aborto y anomalías cromosómicas en el embrión. En la figura 2 se muestran imágenes de núcleos espermáticos analizados. Cada uno de los puntos de color se corresponde con una copia del cromosoma analizado en cada caso. 


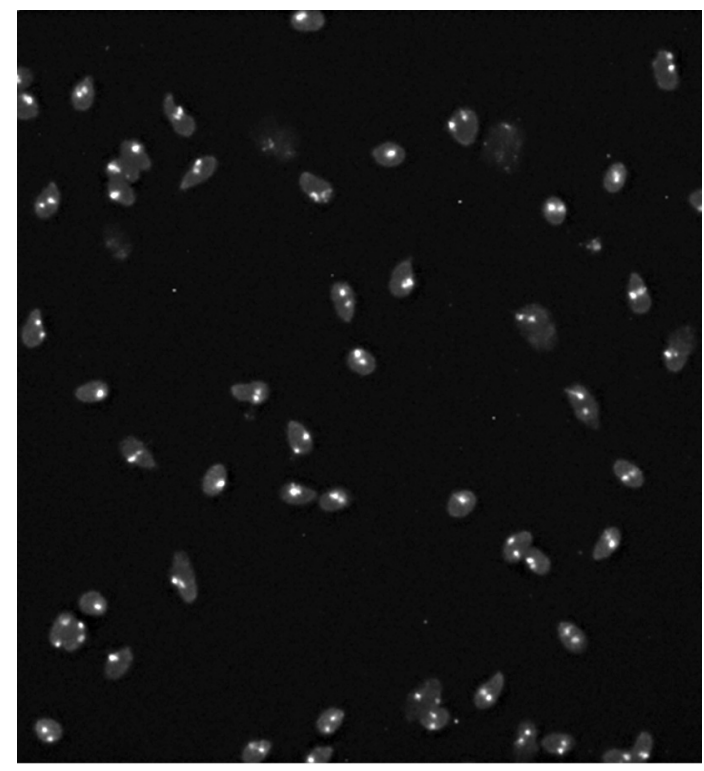

Figura 2. Imagen de núcleos espermáticos.

\subsection{Estudio de la fragmentación del ADN espermático}

Dentro de las valoraciones de lo que se conoce como «factor masculino», uno de los estudios más ampliamente difundido en los últimos años es la evaluación del daño directo del ADN espermático. La integridad del ADN del espermatozoide es de vital importancia para lograr una buena tasa de fecundación, óptima calidad embrionaria, embarazo y mantenimiento a término del mismo. La técnica consiste en establecer si el ADN está integro o fragmentado. Suele aplicarse en casos de hombres con baja movilidad y cantidad de espermatozoides, con varicocele, fumadores severos, hombres con exposición a quimio y/o radioterapia y hombre expuestos a pesticidas o sustancias tóxicas.

\subsection{Estudio de la meiosis}

Los estudios de la meiosis se centran en analizar las diferentes etapas del proceso de la espermatogénesis a escala gonadal. Consiste en analizar una muestra de tejido testicular obtenido mediante biopsia quirúrgica. En este tejido se identifican los diferentes estadios por los que pasan las células germinales espermáticas, con el objeto de detectar eventuales anomalías en alguna de las fases. Estas anomalías, si existen, se documentan y se relacionan con la capacidad reproductiva del paciente. 


\subsection{Estudios somáticos: el cariotipo en el varón}

Como hemos mencionado, los hombres presentan un cariotipo con una fórmula cromosómica 46,XY. Las anomalías cromosómicas numéricas en los autosomas tienen como consecuencia la infertilidad; fallos de implantación, abortos a repetición o nacimientos con defectos genéticos. En los cromosomas sexuales, la anomalía numérica más frecuente es el hombre es el Síndrome de Klinefelter $(47, \mathrm{XXY})$. Estos hombres son azoospérmicos (sin espermatozoides en el eyaculado). Dentro de las anomalías estructurales, las inversiones y translocaciones generan, en su mayoría, importantes problemas durante la espermatogenésis lo cual trae aparejado una baja cantidad y calidad de espermatozoides.

\subsection{Estudio de las microdeleciones del cromosoma $Y$}

El cromosoma $\mathrm{Y}$ es de un tamaño mucho menor que el cromosoma $\mathrm{X}$, sin embargo este cromosoma contiene importantes genes involucrados en la producción de espermatozoides (espermatogénesis) en una región llamada Factor de Azoospermia (AZF). La pérdida del material genético de esa región (deleciones) está asociada a azoospermia (falta total de espermatozoides en eyaculado) u oligozoospermia severa (menos de un millón espermatozoides por mililitro de eyaculado). Para su análisis se ha dividido a la región en 3 zonas AZFa, AZFb, AZFc; en cada una de ellas se estudia la presencia de dos marcadores que indican presencia o ausencia de las mismas. El uso de estos marcadores permite la detección del 90\% de las deleciones reconocidas como clínicamente relevantes. Estos estudios se indican en pacientes azoospérmicos y oligoozpérmicos severos sin causa aparente, con cariotipo normal. Las microdeleciones se encuentran presentes en el 10\% de los pacientes azoospérmicos y el $8 \%$ de los oligozoospérmicos.

\subsection{Estudio del gen CFTR}

Las mutaciones en el gen CFTR dan lugar a una proteína CFTR (del inglés: Cystic fibrosis transmembrane conductance regulator) defectuosa y ocasiona una enfermedad genética conocida como la fibrosis quística (FQ) o mucoviscidosis, la cual se presenta con una alta concentración de cloro y sodio en las secreciones corporales. La FQ es una enfermedad muy severa y frecuente en la población caucásica.

Otra enfermedad asociada a las mutaciones en este gen es la ausencia de vasos deferentes (conductos por los que viaja el eyaculado). Esta última representa entre del 1-2\% de la esterilidad masculina, y está presente hasta en el 25\% de los casos de azoospermia obstructiva. La patología se caracteriza por ausencia bilateral o unilateral de estos vasos deferentes, epidídimo y/o vesículas seminales. Se determina mediante la palpación y/o ecografía testicular. Debido a la alta frecuencia de portadores de mutaciones de la FQ en población general, 
se recomienda realizar el estudio a las parejas femeninas de hombres afectados, para disminuir el riesgo de transmisión de la enfermedad. Es importante realizar el estudio de diversas mutaciones que cubren más del $70 \%$ de los casos de FQ. Para casos con sospecha también se puede realizar el estudio del gen completo a través de secuenciación del mismo. Este estudio esta indicado en pacientes con azoospermia y oligoozpermia obstructivas por ausencia bilateral o unilateral de vasos deferentes, epidídimo y/o vesículas seminales. Se debe descartar agenesia renal. En parejas de afectados y portadores que consultan por planificación familiar. En casos con antecedentes familiares, búsqueda puntual de mutaciones, consanguinidad o bancos de gametos.

\section{EsTUdIOS GENÉTICOS EN LOS EMBRIONES PREIMPLANTACIÓN}

\subsection{El Diagnóstico Genético Preimplantación (DGP) de enfermedades monogénicas}

En algunas ocasiones uno, o los dos miembros de la pareja, es/son portador/ es de una mutación en un gen concreto que les confiere un riesgo alto de trasmitir una enfermedad hereditaria a su descendencia. En estos casos se habla de «riesgo genético». La pareja tiene un riesgo genético concreto en función del tipo de enfermedad de que se trate. Las enfermedades hereditarias se trasmiten siguiendo unos patrones muy bien establecidos, en la mayoría de los casos. El conocimiento del patrón de herencia y la/s mutación/es implicada/s en cada caso, resulta capital para orientar el asesoramiento reproductivo.

Una vez conocida la mutación responsable de la enfermedad, existe una serie de técnicas que nos permiten identificarla en los embriones generados mediante FIV. Brevemente, consiste en el diagnóstico genético de embriones generados mediante técnicas de fecundación in vitro, en estadios muy tempranos de su desarrollo (en fase de 8 células, normalmente), se biopsian los embriones obteniendo una, o muy pocas células. El resultado del análisis de las biopsias se extrapola al resto del embrión, debido a que son células indiferenciadas y por tanto equipotenciales. La finalidad es seleccionar aquellos embriones libres de la mutación/es responsable/s. Los embriones sanos se transfieren al útero materno de forma que se interrumpe el patrón de herencia de la enfermedad. En la figura 3, se muestra de forma esquemática el proceso completo, partiendo desde una pareja afecta, o portadora, de una enfermedad hereditaria grave. En todos los casos se trata de enfermedades graves, sin tratamiento curativo y que, en la mayoría de los casos, son incompatibles con la vida (revisado en Vendrell y Bautista-Llácer., 2013) 


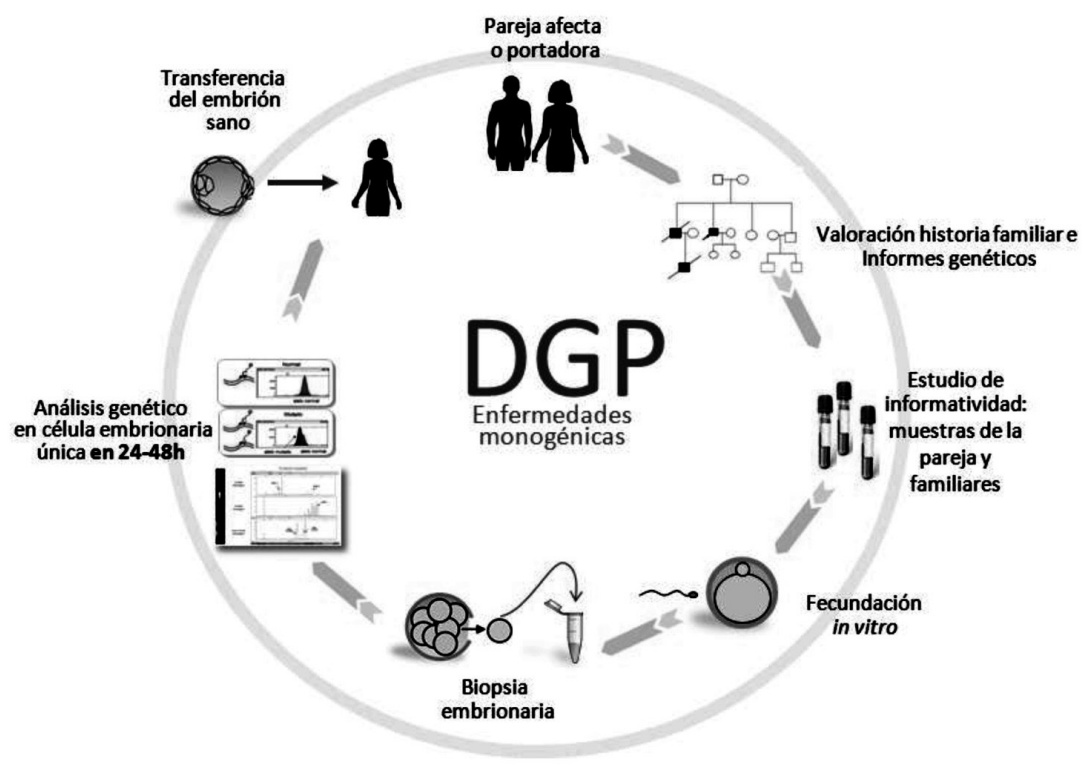

Figura 3. Esquema general de las etapas del DGP en casos de enfermedades hereditarias.

\subsection{El DGP de alteraciones cromosómicas}

En algunas parejas, existe un riesgo genético debido a un reordenamiento cromosómico (mencioando anteriormente). En estos casos, uno de los dos miembros de la pareja es portador asintomático de una alteración cromosómica identificada mediante cariotipo. Los pacientes no suelen tener ningún trastorno, pero algunos de sus ovocitos o espermatozoides son portadores de una formula cromosómica patológica, conocida como «fórmula desequilibrada». Estos gametos alterados dan lugar a embriones alterados que no suelen ser compatibles con la vida, en la mayoría de los casos. Las técnicas de DGP comentadas anteriormente, permiten la selección de embriones sanos o, a lo sumo, portadores de la fórmula equilibrada, en cualquier caso asintomáticos.

\subsection{El DGP de aneuploidías}

En muchos casos, la incapacidad para conseguir un embarazo viene porque la pareja genera embriones con un número de cromosomas distinto al normal. Estos embriones se conocen como «embriones aneuploides». Suelen ser afectados de trisomías (tres copias de alguno de los cromosomas) o monosomías (la perdida de una copia de un cromosoma). Actualmente, existen técnicas de DGP que nos permiten identificar qué embriones son afectos de estas alteraciones y evitar su transferencia al útero materno. 


\section{LOS ESTUDIOS GENÉTICOS PRECONCEPCIÓN}

Como hemos apuntado en la introducción, uno de los principales temores para los futuros padres es tener un hijo con alguna enfermedad. El deseo de los padres que acuden a las clínicas de reproducción es conseguir el nacimiento de un hijo y, en la medida de lo posible, que sea un hijo sano. Este deseo se extiende también a las parejas que tienen un proyecto reproductivo y no conocen su capacidad fértil, porque nunca han intentado concebir. Se puede decir que es un deseo universal. En este sentido, muchas de las enfermedades graves que comprometen seriamente la vida de las personas, tienen una base genética conocida. Además, un gran número de estos trastornos son hereditarios y se trasmiten por parejas completamente asintomáticas.

Según datos de la Organización Mundial de la Salud, uno de cada 1.000 recién nacidos nace con una enfermedad causada por una alteración genética. Se estima que son cerca de unas 10.000 enfermedades. Los registros de los datos de atención primaria muestran que un $40 \%$ de los casos atendidos en los servicios de Pediatría se deben a alguna de estas enfermedades. Además, muchas se dan con muy poca frecuencia en la población, de forma que su diagnóstico y posible tratamiento es extremadamente complejo. Son las enfermedades poco prevalentes que se conocen coloquialmente como «enfermedades raras», pero que en su conjunto afectan a unos 30 millones de personas en Europa (ampliado en Weely y Leufkens, 2013).

\subsection{El concepto del «riesgo genético»}

En este escenario, es cada vez más frecuente que muchas parejas muestren su interés en saber cuál es el riesgo que tienen de trasmitir una de estas enfermedades a su descendencia. Las enfermedades más difíciles de prever son las que conocemos como enfermedades de «herencia recesiva». Son aquellas enfermedades en las que el padre y la madre son portadores de alguna mutación, que no les afecta a ellos, pero que afectará a su descendencia si se heredan de forma conjunta. Todos los hijos que hereden las dos mutaciones manifestarán la enfermedad. Se estima que todos somos portadores de unas 10 mutaciones patogénicas (capaces de causar una enfermedad). Por otro lado, existe otro grupo de enfermedades difíciles de predecir, que son las enfermedades con una herencia «ligada al cromosoma X». Estas enfermedades son trasmitidas por mujeres portadoras, que son asintomáticas, y las padecen sus hijos varones. En cualquiera de los dos casos, las parejas portadoras se conocen como parejas de riesgo genético y deben recibir un adecuado asesoramiento genético antes de la primera concepción.

En los últimos años, los avances científicos en el campo de la Genética nos han permitido profundizar de forma espectacular en el conocimiento de los genes y las enfermedades de base genética. La evolución de la Genética viene de la mano de una serie de avances tecnológicos espectaculares. Uno de los 
avances más significativos es el conocimiento de la secuencia completa de todos los genes de un individuo, lo que conocemos como el «genoma», en el año 2003 dentro de lo que se conoció «Proyecto Genoma Humano» (Más información en: https://www.genome.gov/10001772/all-about-the--human-genome-projecthgp/). Llegados a este punto resulta relevante establecer la diferencia entre la Genética y la Genómica. Podemos decir que la Genética es el estudio de los genes de forma individual (gen a gen) y la Genómica es la disciplina que estudia todos los genes de forma conjunta, sus interacciones, su evolución y su origen. Gran parte de los avances en este campo del conocimiento ha venido de la mano de los desarrollos tecnológicos, que nos permiten interrogar la secuencia del genoma de un individuo en unos pocos días. La técnica más revolucionaria y más reciente es la que conocemos como «secuenciación masiva», que permite conocer la secuencia de uno o más genomas de forma simultánea e identificar mutaciones, comparando todo o parte del genoma de un paciente con un genoma de referencia. De esta manera podemos encontrar mutaciones de una manera rápida y precisa.

\subsection{La planificación familiar y la Genómica}

La aplicación de estudios genómicos en parejas con deseo reproductivo ha abierto un campo nuevo dentro del concepto de la planificación familiar. Empieza a ser habitual que las parejas asintomáticas consulten por un estudio genético masivo, con el objeto de conocer si son portadores de alguna mutación patogénica que puedan trasmitir a sus futuros hijos y, en su caso, conocer con detalle cuales son las opciones reproductivas para evitar esta trasmisión. Este análisis genómico cobra especial valor en las parejas que acuden a la donación de gametos (óvulos o espermatozoides) por problemas de fertilidad. En estos casos, existe un precepto legal recogido en la Ley de Reproducción Humana Asistida (Ley 14/2006) que obliga a los centros de reproducción a asegurar al máximo la salud de la descendencia generada mediante la donación de gametos. Este hecho, junto con la demanda social, ha propiciado que los laboratorios de Genética hayan diseñado distintos paneles de análisis masivo de muchos genes, responsables de muchas enfermedades. Estos estudios se conocen como «estudios genéticos preconcepción» (revisado por Lazarin y Haque, 2016).

En términos generales, estos paneles contemplan dos escenarios. En primer lugar, si se trata de una pareja que quiere conocer su estatus genético antes de la concepción con gametos propios, se procede al análisis por separado de la carga genética de cada miembro de la pareja. Posteriormente se cruzan los datos genéticos de ambos miembros y, en caso que compartan mutaciones en los mismos genes, se informa del riesgo genético para la descendencia. En estos casos se trata de enfermedades de herencia recesiva o ligada al cromosoma X.

El otro escenario son las parejas que necesitan una donación de gametos. En este caso, se analizan separadamente a los donantes (tanto de ovocitos como de espermatozoides) y al miembro de la pareja que va a aportar el gameto para la reproducción. Posteriormente, se cruzan los datos genómicos y se identifica 
cual es el donante que no comparte mutaciones en los mismos genes que el paciente. Este donante se establecerá como «donante idóneo» y se podrá realizar la donación con un riesgo genético extremadamente menor.

Es muy importante destacar el papel del asesoramiento genético preconcepción en estos casos. Este tipo de asesoramiento consiste en una consulta en la que se trate de forma tranquila y no dirigida, aspectos como el riesgo genético, el modelo de herencia del trastorno de que se trate, cómo afectaría a la futura descendencia la enfermedad concreta y las opciones reproductivas existentes en cada caso. Estas consultas deben realizarse en un contexto relajado y en el que se resuelvan todas las dudas de la pareja. El entendimiento de todos estos aspectos es clave para la toma de decisiones y resulta de capital importancia para el proyecto reproductivo de cada pareja, debido a su implicación a largo plazo para la salud de la descendencia. Asimismo, resulta de especial relevancia indicar que el tipo de panel, los genes que se incluyen, las mutaciones que son capaces de detectar, las enfermedades implicadas y los límites de detección, son aspectos clave en este tipo de análisis y deben ser explicados de forma precisa y entendible por las parejas que se van a someter a estos estudios.

Por último, estos estudios no excluyen el riesgo de trasmitir enfermedades de forma absoluta. Existen mutaciones que no se pueden detectar con la tecnología utilizada, así como mutaciones que aparecen por primera vez en la descendencia y que no son heredadas (mutaciones de novo). Todos estos aspectos deben ser debidamente clarificados, estimando el «riesgo residual» para cada enfermedad.

\section{Comentarios Finales}

Como hemos visto, el ámbito de la Genética se encuentra estrechamente relacionado con el campo reproductivo. Determinados trastornos genéticos en los progenitores pueden ser causa de infertilidad o de problemas congénitos en la descendencia. El asesoramiento genético en medicina reproductiva es crucial y ayuda a evaluar el riesgo que se manifieste o se repita una determinada enfermedad. Al mismo tiempo, permite transmitir a los futuros progenitores el pronóstico familiar en cuanto a su descendencia e indicar técnicas de estudio apropiadas para cada caso. En conclusión, podemos decir que los estudios genómicos en el campo de la Medicina Reproductiva nos permiten introducir el concepto de «anticipación» en la toma de decisiones y son una herramienta clave en el contexto de la medicina preventiva.

\section{REFERENCIAS BIBLIOGRÁFICAS}

Apter, S., Bauquis, V. B., Evers, H., Farquharson, R., Lundin, K., Macklon, N., Tapanainen. J., Vassena. R., Veiga. A., Brown. S., Focus on Reproduction, Septiembre 2016: 19. 
Christians, E., Davis, A. A., Thomas, S.D., Benjamin, I. J., «Maternal effect of Hsf1 on reproductive success», en: Nature, 2000; 407(6805): 693-4.

FrYNS J. P., «Van Buggenhout G. Structural chromosome rearrangements in couples with recurrent fetal wastage», in: Eur J Obstet Gynecol Reprod Biol, 1998 Dec, 81(2): pp. 171-6.

Gersen, S. L. y Keagle, M. B., "The Principles of Clinical Cytogenetics» en: Humana Press Inc. Totowa, NJ. 2013.

Grynberg, M., Bidet, M., Benard, J., Poulain, M., Sonigo, C., Cédrin-Durnerin, I., Polak, M., «Fertility preservation in Turner syndrome», en: Fertil Steril, 2016, Jan, 105(1): 13-9.

Holly B Ford, and Danny J Schust, MD. «Recurrent Pregnancy Loss: Etiology, Diagnosis, and Therapy», in: Rev Obstet Gynecol, 2009, Spring, 2(2), pp. 76-83.

Kupka, T., D’Hooghe, A.P., Ferraretti, J., de Mouzon, K., Erb, J. A., Castilla, C., CalhazJorge, C., De Geyter, CH., Goossens, V., «Assisted reproductive technology in Europe, 2011: results generated from European registers by ESHRE», en: The European IVF-monitoring (EIM) Consortium for the European Society of Human Reproduction and Embryology (ESHRE), First published online: January 5, 2016 Hum. Reprod. (2016) 31 (2): 233-248).

Lazarin, G. A., Haque, I.S., «Expanded carrier screening: A review of early implementation and literature», en: Semin Perinatol, 2016 Feb; 40(1): 29-34.

Neto, F. T., Bach, P.V., Najari, B. B., Li, P. S., Goldstein, M., «Genetics of Male Infertility", en: Curr Urol Rep, 2016 Oct;17(10):70.

Soini, S., Ibarreta, D., Anastasiadou, V., Aymé, S., Braga, S., Cornel, M., Coviello, D., EversKiebooms, G., Geraedts, J., Gianaroli, L., Harper, J., Kosztolanyi, G., Lundin, K., Rodrigues-Cerezo, E., Sermon, K., Sequeiros, J., Tranebjaerg, L. y KäÄriäinen, H., «The interface between assisted reproductive technologies and genetics: technical, social, ethical and legal issues», en: European Journal of Human Genetics, 2006, 14, 588-645.

Venkatesh, T., Suresh, P. S., and Tsutsumi, R., «New insights into the genetic basis of infertility», en: Appl Clin Genet, 2014; 7: 235-243.

Tong, Z. B., Gold, L., Pfeifer, KE., Dorward, H., Lee, E., Bondy CA, Dean, J., Nelson, L. M., «Mater, a maternal effect gene required for early embryonic development in mice», in: Nat Genet, 2000; 26(3):267-8.

Van Weely, S. y LeufKens H. G. M., "A Public Health Approach to Innovation» en: Priority Medicines for Europe and the World. Update on 2004. Background Paper Background Paper 6.19 Rare Diseases. WHO: http://www.who.int/medicines/areas/ priority_medicines/BP6_19Rare.pdf.

VendRell, X y BAUTISTA-LlÁcER, R., "A molecular overview on preimplatation genetic diagnosis and screening: a molecular future?» en: System Biology in Reproductive Medicine, 2012; 58(6):289-300.

Vendrell X., Ferrer M., García-Mengual E., Muñoz P., Triviño, J.C., Calatayud, C., Rawe, V., Ruiz-Jorro, M., "Correlation between aneuploidy, apoptotic markers and DNA fragmentation in spermatozoa from normozoospermic patients», en: RBM Online, 2014; 28:492-502.

VendRell, X., "Genes de efecto materno», en: Bases moleculares de la fecundación humana, Editorial Médica, 2013, pp. 47-75.

Unidad de Genética Reproductiva, Sistemas Genómicos

XAVIER VENDRELL

Parque Tecnológico de Valencia

Ronda G. Marconi 6, 46980 Paterna (Valencia)

[Artículo aprobado para publicación en diciembre de 2016] 